\title{
Analysis of the Learners' Problems of Previous Primers Being Used in Different Literacy Centers
}

\author{
${ }^{a}$ Nusrat Nawaz Abbasi, ${ }^{b}$ Rifat Tahira, ${ }^{c}$ Muhammad Sami ur Rehman, ${ }^{d}$ Sualeha Zafar \\ a Assistant Professor, Department of Education, The Government Sadiq College Women University Bahawalpur, \\ Pakistan \\ Email: nusratnawaz19@gmail.com \\ ${ }^{\mathrm{b}}$ Assistant Professor, Department of Education, The Islamia University of Bahawalpur, Pakistan \\ Email: riffat.tahira@iub.edu.pk \\ ${ }^{\mathrm{c}}$ Subject Specialist, Govt Abbasia Higher Secondary School Bahawalpur , Pakistan \\ Email: samibwp10@gmail.com \\ ${ }^{\mathrm{d}}$ Lecturer, Department of Education, The Government Sadiq College Women University Bahawalpur, Pakistan \\ Email: sualeha@gscwu.edu.pk
}

\begin{tabular}{l}
\hline ARTICLE DETAILS \\
\hline History: \\
Accepted 26 July 2021 \\
Available Online September 2021
\end{tabular}

Keywords:

Learners' Problems, Adult Literacy, Literacy Centers, Literacy Objectives

JEL Classification:

I21,

DOI: $10.47067 /$ real.v4i3.179

\section{ABSTRACT}

The former primers being employed in various literacy centers were evaluated on the basis of contents and literacy objectives. Current study being descriptive in nature comprised self-developed questionnaire. The responses obtained from the questionnaire were fed in Microsoft excel programmes. Questionnaire using five-point Likert scale, having close ended responses were developed by researcher through consulting related researches, by making basis the literature review. After determining validity and reliability of research tool, the researcher personally visited and administered questionnaire from the selected respondents. To analyze the data, the statistical package for Social Science (SPSS) was utilized by using formulas. The results that were attained were stated in the form of tables and figures. The conclusions and interpretations drawn from these results were also stated. Major findings of the study were the students' responses and teachers feel that the existing primer is pleasing.

(C) 2021 The authors. Published by SPCRD Global Publishing. This is an open access article under the Creative Commons AttributionNonCommercial 4.0

Corresponding author's email address: nusratnawaz19@gmail.com

\section{Introduction}

The only thing that the adult literacy program offers is in its original form. A primer should not only aim to develop reading skills and enhance writing abilities, but it should also speak and listen. It looks like a primer and is a tool for developing simple learning materials. Even the most important literacy program depends on the first program because if most of the literacy program fails rather than perhaps completing the foundation it can be one of the keys to success. Different primers are used in adult literacy centers and various authors carefully review these original books. First we will see the 
perspective of the following writers in the first sense.

The above description shows that the primer is similar to the basic covering that covers the parts of the story. So early literacy books are like basic textbooks. The Encarta Dictionary considers the primer to be,

1: Basic textbook: a book used to teach young children to read, usually contains simple stories 2: Introductory text: a letter that provides an introduction to the topic.

Primer is a basic textbook or basic textbook for teaching people basic reading and writing skills. (UNESCO and the Asia / Pacific Cultural Center, 1997)

This explanation indicates that the primer is the only basic textbook and that it does not pay attention to the ability to write. A primer is a book, or series of books, containing textbooks for beginners or literate students. Primers are also tools used to teach literacy equally. Or a primer is usually designed to be used in a specific learning method (Halvorson and Borneman, 1992).

Primer or primer series usually consists of several parts with different functions. We can classify primers into different categories but they look solid and consistent. The following author also reproduces this idea.

Bhat (1992) holds the view,

"Primers contain elementary and other elementary elements, which continue to be the most popular format these days even though their durability has been criticized."

Most primers are designed in the same way. These primers do not change and the author does not agree with the durability of this first. Although these primers are criticized they still play an important role in the growth of adult students.

Waters (1992) noted that "Pre-initiation activities: Designed for people with little or no knowledge of reading and writing, focusing on skills." Basic: Designed for people with reading and working skills who focus on word-attack skills, certain basic cognitive skills, and basic literacy skills.

Mohanty (2002) described the aims and objectives of primers as follows; Primers have different purposes and objectives depending on the needs and circumstances of the students. These are the following:

i. Continuous development of reading ability.

ii. Recreation and entertainment.

iii. Provision of useful information and information

iv. Teaching skills and techniques.

$\mathrm{v}$. The introduction of new ideas and the formation of ideas.

vi. Structure, modification or modification of attitude.

vii. Development of judgment, discrimination and sensitive areas.

Stanley (2004) noted that in Zambia the content of the primer was developed not only for the development of basic skills but also aimed at empowering communities to prevent or control common chronic diseases. The alternative is enhanced by the development of local building materials that focus on local elders, local culture, and community issues. Developing basic literacy skills is more important 
than other learning basics because things in a systematic way can be accessed by learners. They don't know what's best to learn so it's hard to produce their own.

A key tool for both learning campaigns was the foundation established by teachers, in consultation with the transformation leadership. It will be noted at this stage that there was obviously no discussion with illiterate people regarding the content of these early books.

Alysha Trinca (1990) argued that adult literacy is the most advanced and most readily available when the interests of the uneducated are of paramount importance. It also holds that an uneducated adult, unlike a child, has full names and a rich source of life experience that you can draw and learn from. The first variations in adult writing were either based on the development of basic literacy skills or had specific themes.

This starts with fifty-six pages. In this beginning there is no introduction, which guides the principles of its construction. These key points are highlighted in the assessment of this foundation.

The names are given with their appropriate pictures, and these names are divided into sections. The alphabet combined with the alphabet learned to form words and sentences. The distinctive sounds of the Haroof Illat are made prominent in the combination of words. The words used in this introduction seem appropriate because on this basis the use of such words can express different grammatical terms. If the author ends up looking at other features it can be a better start.

Some images actually did not represent a specific name or these images could not provide the required definitions. An example is a picture suitable for the words of Warris Dadoo (). Secondly the word given before the picture, which shows that the reader can read the word and the picture helps to explain the meaning of the word.

These first words are divided into sections and combined with the learned alphabet. These alphabets, combined with those of the learned, were not previously taught. While the sounds of the alphabet do not read differently the learning process cannot be completed, or these words are used in the construction of words. So this feature was not retained and the words were made with those letters, which had not been taught before. Also amazing is the fact that some of the pages in sequence, with pictures and captions for this first book and Naya Din are very relevant. It seems like someone is putting in some important copy. (System of Literacy and Informal Education, Quetta Department of Social Development).

At the beginning the word is written and the reader has to separate his words and some words are formed to combine his words with others. Vowels are involved in all words.

The goal, see things and in addition to seeing is not used here. The name is given first, which is unusual for students. If the image is displayed before the word, then we can refer to the visual and auditory images. The principle, the meaning does not work properly .The principle of vision and knowledge is not specified in this beginning. The image, given after the name, did not meet the need to identify and recognize the goal.

Speaking of pictures, here one of them shows a picture of a girl, calling another, and the appropriate words are written appa ajaa () the same pattern is used on the next page. On page number nine the correct words are given around the picture. This image did not indicate which part of these 
words you are entitled to. Some names are given in this beginning without teaching their names. For example on page seven the word yaad () is given and the letters of the word are not taught on the previous page. The same situation is given on page eight as the word koo joo yeh () is pronounced.

It can therefore be said that the power of many people must work in this practice and that large sums of money must be raised and strengthened so that good products can be rewarded and the poor can be criticized. Outstanding examples among building materials, organizations and individuals should be awarded prizes, while institutions and individuals should be held accountable or punished for substandard materials.

Literacy resources should always be provided to targeted students. With more than two-thirds of illiterate women being women, their needs must be taken into account in order for resources to be accepted and appreciated by students. Many of the things that were created in the past are now obsolete and the content is very old. The rapid development of times requires the improvement of building materials. New items must be constantly produced and updated and developed for community development.

The Objectives of Study are:

- To analyze the learners problems of previous primers being used in different literacy centers.

- To review the contents of previous primers being used in different literacy centers

\section{Research Procedure}

\subsection{Data Collection Instrument}

In this study questionnaire was used as a tool of data collection because of a large number of respondents and shortage of time. The study was conducted on the adult literates and teachers available in literacy centers of rural and urban areas of Bahawalpur, Khanewal districts. All the adults' literacy centers of above-mentioned two districts were considered as a sample for this study. Random sampling technique is appropriate for the concerned study the sample of people or events surveyed must be carefully chosen and described. In this study number of total population and the selected sample is mentioned below.

Table No. 3.1 showing the sampling size

\begin{tabular}{|l|c|c|}
\hline Name of population & Number of total population & Number of sample size \\
\hline Adult learners & 4200 & 300 \\
\hline Teachers & 140 & 100 \\
\hline
\end{tabular}

Above mentioned districts literacy centers population are the sample size of this study, data is equally taken from Bhawalpur and Khanawal areas from teachers and adult learners accordingly. Following are the literacy centers working in district Bahawalpur and Khanewal.

\subsection{Questionnaire Construction \& Administration}

The questionnaire was also improved in the light of opinion taken by some experts. The questionnaires were administrated to the sample of four hundred literacy learners and literacy teachers, teachers filled the questionnaires and from learners researcher.

\subsection{Data Analysis}


After collecting data from literates and the teachers. Data was fed in the form of zero and one, correct response was fed as one and wrong regarded as zero. It is the qualitative research that's why percentage technique was used to analyze the data.

\section{Results}

Table (1) Interest in Present Primer

\begin{tabular}{|l|l|l|l|l|l|}
\hline Item. & $\begin{array}{l}\text { Statement of } \\
\text { Question }\end{array}$ & Subjects & Yes. & No. & $\begin{array}{l}\text { To } \\
\text { extent }\end{array}$ \\
\hline \multirow{2}{*}{ Q. No.1 } & $\begin{array}{l}\text { Do you feel } \\
\text { existing primer } \\
\text { interesting? }\end{array}$ & \multirow{2}{*}{ Learners } & 60 & 81 & 159 \\
\cline { 3 - 6 } & \multirow{2}{*}{ Teachers } & $43 \%$ & $27 \%$ & $53 \%$ \\
\cline { 3 - 6 } & & $43 \%$ & 4 & 53 \\
\cline { 3 - 6 } & Total \%age & $103(26 \%)$ & $85(21 \%)$ & $\mathbf{2 1 2}(53 \%)$ \\
\hline
\end{tabular}

\section{Figure (4.1)}

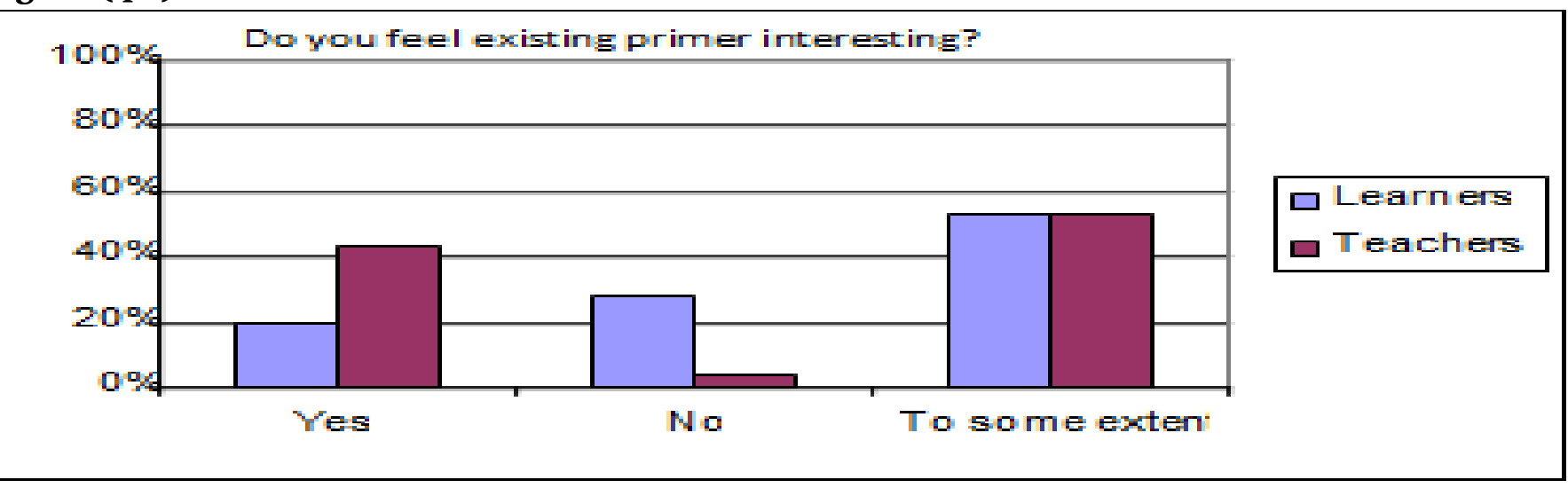

It is clear from table (1) that 53\% of respondents agreed with the current investigation, among these $20 \%$ of students. $27 \%$ of respondents were of the view that they are not interested in the first letter available. It is evident from the third option that about $53 \%$ of the students seem to believe that the primer that exists currently is somewhat interesting.

The first option showed that $43 \%$ of the subjects who responded agreed with the first letter available. $27 \%$ of respondents were of the opinion that they were not interested in the primers that exist presently. It can be seen from the third option that about 53\% subjects, from 8 students' questionnaire evaluation felt that the current primer was somewhat appealing.

The first option shows that $26 \%$ of respondents prefer the first start. $21 \%$ of the subjects who filled out the questionnaire did not seem to be interested in existing primer. It is observed from third option, $53 \%$ of students and teachers are of view that the present primer is pleasing. 
Table (2) Content and Appearance of Primer

\begin{tabular}{|l|l|l|l|l|l|l|}
\hline Item. & $\begin{array}{l}\text { Statement of } \\
\text { Question }\end{array}$ & Subjects & Easy. & Simple. & Attractive. & Difficult \\
\hline $\begin{array}{l}\text { Q. } \\
\text { No.2 }\end{array}$ & $\begin{array}{l}\text { How do you } \\
\text { feel } \\
\text { existing } \\
\text { primer? }\end{array}$ & \multirow{2}{*}{ Learners } & 50 & 231 & 6 & 13 \\
\cline { 3 - 7 } & \multirow{2}{*}{ Teachers } & 8 & $77 \%$ & $2 \%$ & 30 & $4 \%$ \\
\cline { 3 - 7 } & & & $8 \%$ & $45 \%$ & $30 \%$ & 17 \\
\cline { 3 - 7 } & Total \%age & $58(14 \%)$ & $276(69 \%)$ & $36(9 \%)$ & $32(8 \%)$ \\
\hline
\end{tabular}

Figure (4.2)

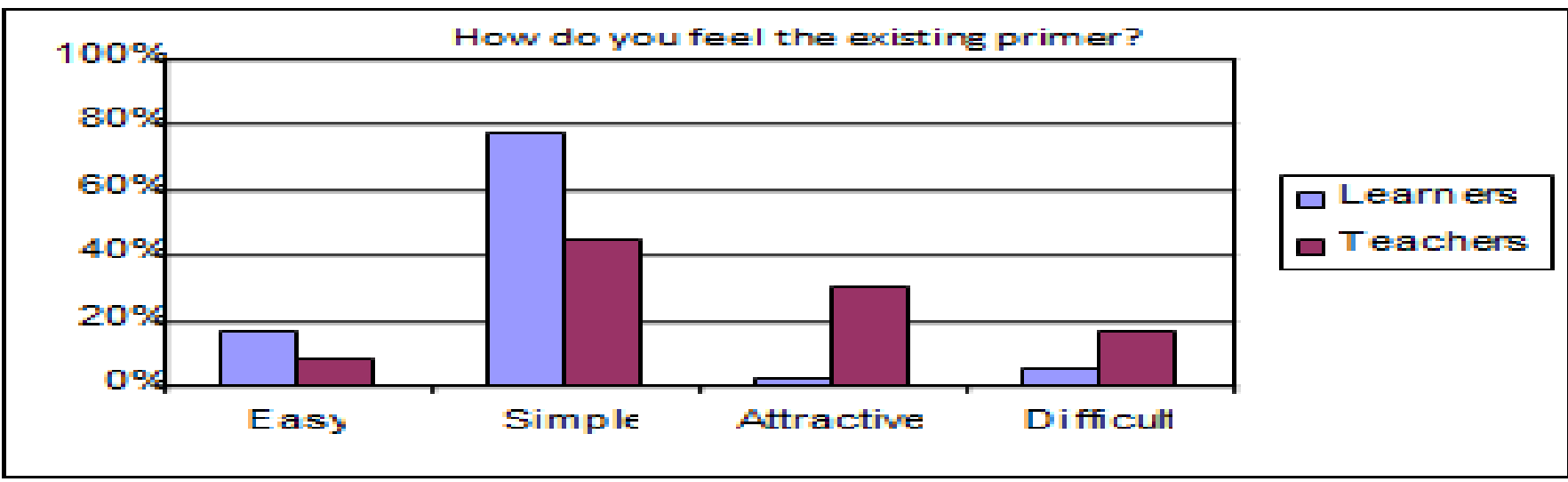

Majority of the learners and teachers were of the opinion that the exercises included in the primer were easy. Hence the percentage of the responses we received about this option was $69 \%$. The first option states that $14 \%$ learners and teachers mentioned that the present primer was easy to read. $9 \%$ learners and teachers comments that there primer was difficult. In the fourth option $8 \%$ learners and teachers consider it very attractive.

\subsection{Words include in the Existing primer}

Table (4.3) In Reading Context

\begin{tabular}{|l|l|l|l|l|l|l|}
\hline Item. & $\begin{array}{l}\text { Statement of } \\
\text { Question }\end{array}$ & Subjects & Easy & Very easy & Difficult & $\begin{array}{l}\text { Very } \\
\text { difficult. }\end{array}$ \\
\hline $\begin{array}{l}\text { Q. } \\
\text { No.3 }\end{array}$ & $\begin{array}{l}\text { How do you } \\
\text { feel the words } \\
\text { includes in the } \\
\text { existing } \\
\text { primer? }\end{array}$ & \multirow{2}{*}{ a) } & 201 & 12 & 85 & 2 \\
\cline { 3 - 7 } & Teachers & $67 \%$ & $4 \%$ & $28 \%$ & $1 \%$ \\
\cline { 3 - 7 } & & $38 \%$ & 28 & 34 & 0 \\
\cline { 3 - 7 } & Total \%age & $239(60 \%)$ & $40(10 \%)$ & $119(30 \%)$ & $2(0 \%)$ \\
\hline
\end{tabular}


Figure (4.3)

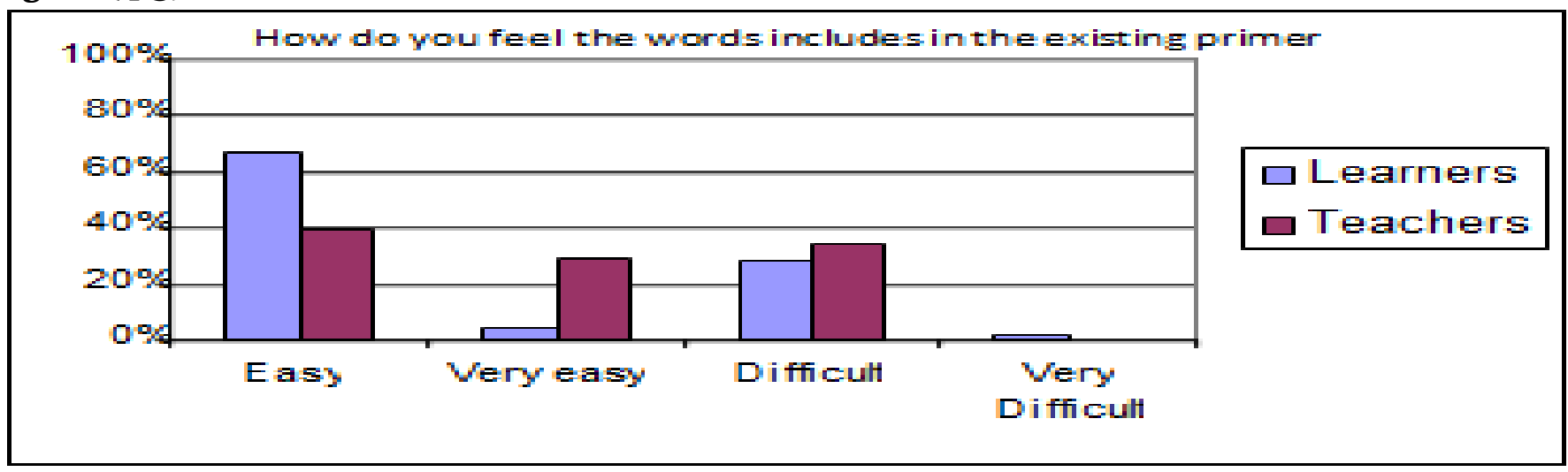

$60 \%$ of the respondents including learners and teachers, agreed that the wording of the existing primer was easy. The number of these learners and teachers were $10 \%$ learners and teachers give importance to the second option and said that words includes in the present primer were very easy. The third option indicates that $30 \%$ learners and were disagree with others and said that these words were difficult to learn for them and o\% no one consider it very difficult.

\subsection{Words include in the Existing primer}

Table (4.4) In writing Context

\begin{tabular}{|c|c|c|c|c|c|c|}
\hline Item. & $\begin{array}{l}\text { Statement of } \\
\text { Question }\end{array}$ & Subjects & Easy & Very easy & Difficult & $\begin{array}{l}\text { Very } \\
\text { difficult. }\end{array}$ \\
\hline \multirow[t]{5}{*}{ Q. No.4 } & \multirow{5}{*}{$\begin{array}{l}\text { How do you feel } \\
\text { the words } \\
\text { includes in the } \\
\text { existing primer? }\end{array}$} & \multirow{2}{*}{ Learners } & 49 & 30 & 199 & 22 \\
\hline & & & $16 \%$ & $10 \%$ & $67 \%$ & $7 \%$ \\
\hline & & \multirow{2}{*}{ Teachers } & 24 & 4 & 61 & 11 \\
\hline & & & $24 \%$ & $4 \%$ & $61 \%$ & $11 \%$ \\
\hline & & Total \%age & $73(18 \%)$ & $34(9 \%)$ & $260(65 \%)$ & $33(8 \%)$ \\
\hline
\end{tabular}

Figure (4.4)

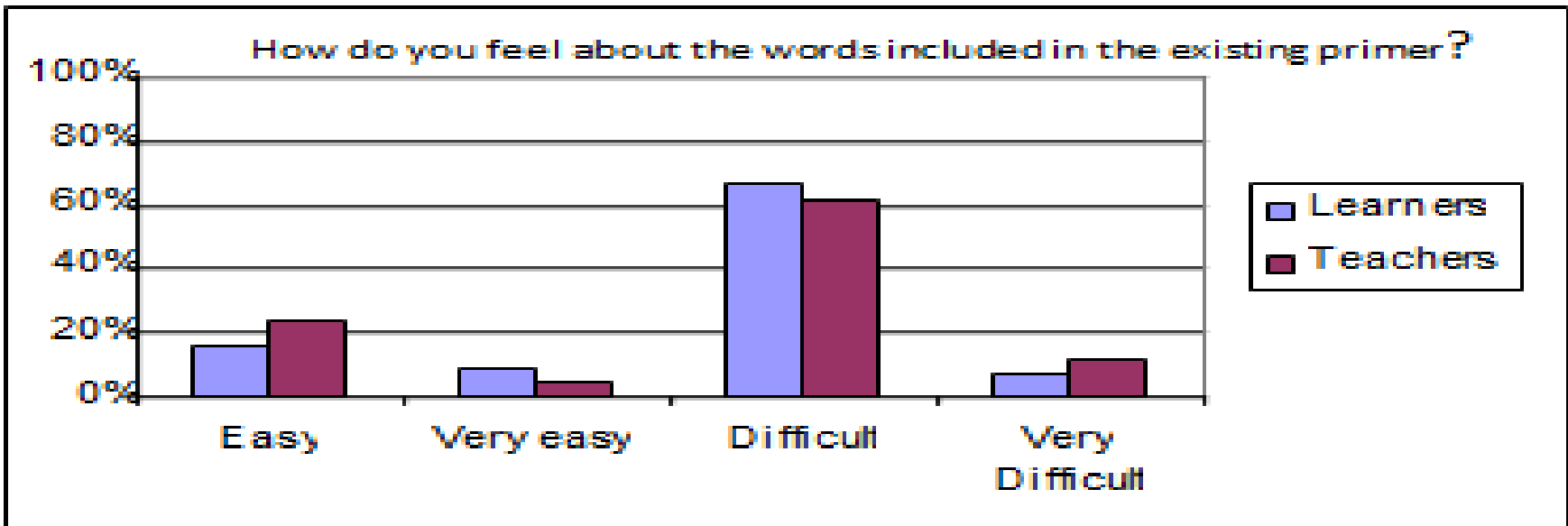

As the Table (4.30) showed thst16\% learners preferred the first option and felt the words include in the existing primer are easy to write. Though $10 \%$ learners recommended these words very easy. Majority of $67 \%$ learners give valued to this option and consider the word in the primer difficult to write. Only $7 \%$ responses were mentioned from the adults' learners and felt these words very 
difficult.

As the Table (4.30) demonstrate thst $24 \%$ teachers preferred the first option and felt the words include in the existing primer are easy to write. Though $4 \%$ recommended these words very easy to write. Majority of learners and teachers give valued to this option and consider the word in the primer difficult to write among these 61\%teachers. Only $11 \%$ responses were mentioned from the adults' learners and felt these words very difficult.

\subsection{Sentences in the Existing primer}

Table (4.5) (In reading Context.)

\begin{tabular}{|c|c|c|c|c|c|c|}
\hline Item. & Statement of Question & Subjects & Easy & Very easy & Difficult & Very difficult. \\
\hline \multirow{5}{*}{$\begin{array}{l}\text { Q. } \\
\text { No.5 }\end{array}$} & \multirow{5}{*}{$\begin{array}{l}\text { How do you feel the } \\
\text { sentences included in } \\
\text { the existing primer? }\end{array}$} & \multirow{2}{*}{ Learners } & 210 & 8 & 77 & 5 \\
\hline & & & $70 \%$ & $3 \%$ & $25 \%$ & $2 \%$ \\
\hline & & \multirow{2}{*}{ Teachers } & 47 & 8 & 45 & $\mathrm{O}$ \\
\hline & & & $47 \%$ & $8 \%$ & $45 \%$ & O\% \\
\hline & & Total \%age & $257(64 \%)$ & $16(4 \%)$ & $122(31 \%)$ & $5(1 \%)$ \\
\hline
\end{tabular}

\section{Figure (4.5)}

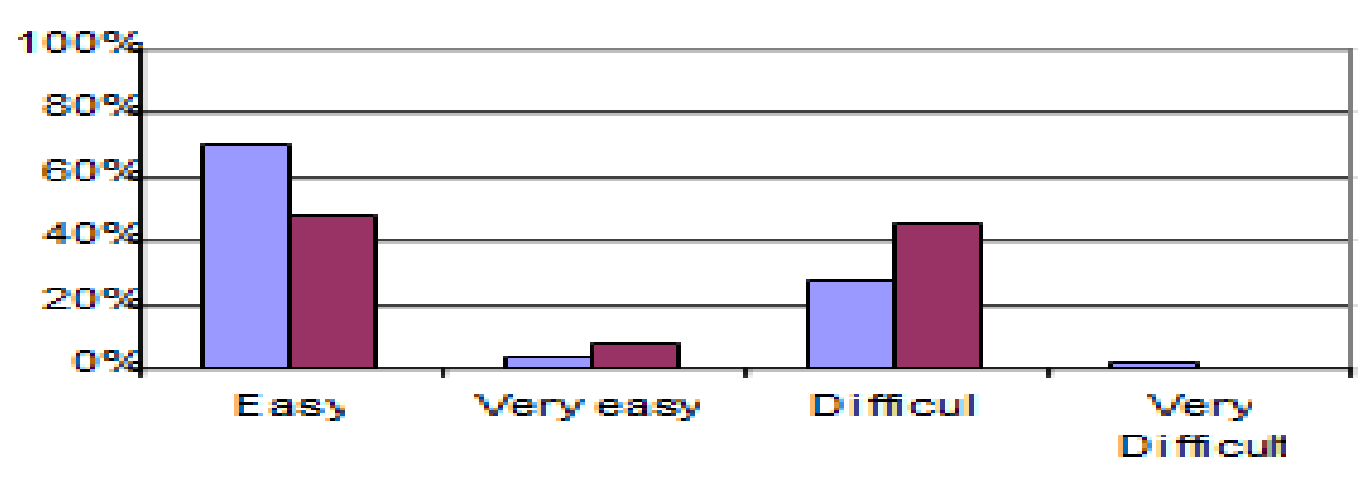

By means of reading the sentences $64 \%$ learners and teachers suggest these words easy to read. Considering the structure of sentences $31 \%$ deemed the sentence formation as rather hard. $1 \%$ response was given from teachers and learners about the fourth option.

\subsection{Sentences include in the Existing primer}

Table (4.6) In writing Context

\begin{tabular}{|c|c|c|c|c|c|c|}
\hline Item. & $\begin{array}{l}\text { Statement of } \\
\text { Question }\end{array}$ & Subjects & Easy & Very easy & Difficult & \begin{tabular}{|l} 
Very \\
difficult.
\end{tabular} \\
\hline \multirow{5}{*}{$\begin{array}{l}\text { Q. } \\
\text { No.6 }\end{array}$} & \multirow{5}{*}{$\begin{array}{l}\text { What do you } \\
\text { think about } \\
\text { the sentences } \\
\text { included in } \\
\text { the existing } \\
\text { primer? }\end{array}$} & \multirow{2}{*}{ Learners } & 30 & 29 & 26 & 215 \\
\hline & & & $10 \%$ & $10 \%$ & $9 \%$ & $72 \%$ \\
\hline & & \multirow{2}{*}{ Teachers } & 10 & 43 & 8 & 35 \\
\hline & & & $10 \%$ & $43 \%$ & $8 \%$ & $35 \%$ \\
\hline & & Total \%age & $40(10 \%)$ & $72(18 \%)$ & $26(9 \%)$ & $262(63 \%)$ \\
\hline
\end{tabular}




\section{Figure (4.6)}

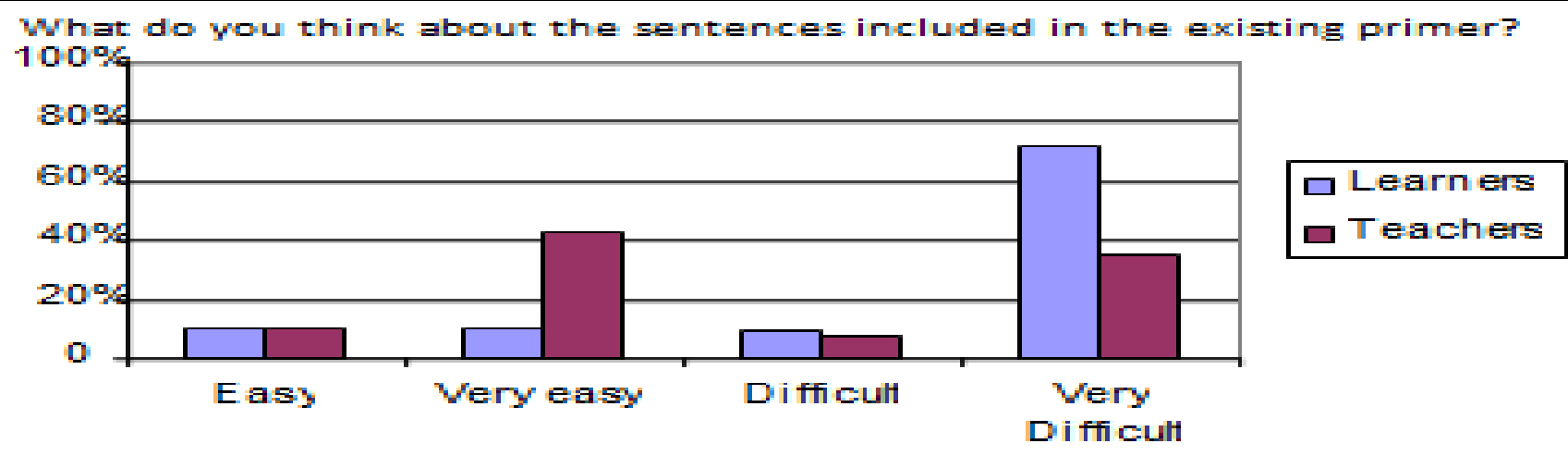

By means of writing the sentences $6 \%$ feel it difficult in which $9 \%$ were learners and $8 \%$ teachers. Regarding the sentence structure, $72 \%$ of the learners and 35\% of teachers were of view that the sentence formation was hard. No response was given from teachers about the fourth option so the results from teachers were mentioned as zero.

Table (4.7) Review of previous primer regarding exercises

\begin{tabular}{|c|c|c|c|c|c|}
\hline Item. & $\begin{array}{l}\text { Statement of } \\
\text { Question }\end{array}$ & Subjects & Yes. & No. & $\begin{array}{l}\text { To some } \\
\text { extent }\end{array}$ \\
\hline \multirow[t]{5}{*}{ Q. No.7 } & \multirow{5}{*}{\begin{tabular}{|l|} 
The exercises \\
include in the \\
previous primer \\
are easy to \\
develop the \\
writing skill
\end{tabular}} & \multirow{2}{*}{ Learners } & 69 & 6 & 225 \\
\hline & & & $23 \%$ & $2 \%$ & $75 \%$ \\
\hline & & \multirow{2}{*}{ Teachers } & 11 & 34 & 55 \\
\hline & & & $11 \%$ & $34 \%$ & $55 \%$ \\
\hline & & Total \%age & $80(20 \%)$ & $40(10 \%)$ & $280(70 \%)$ \\
\hline
\end{tabular}

Figure (4.7)

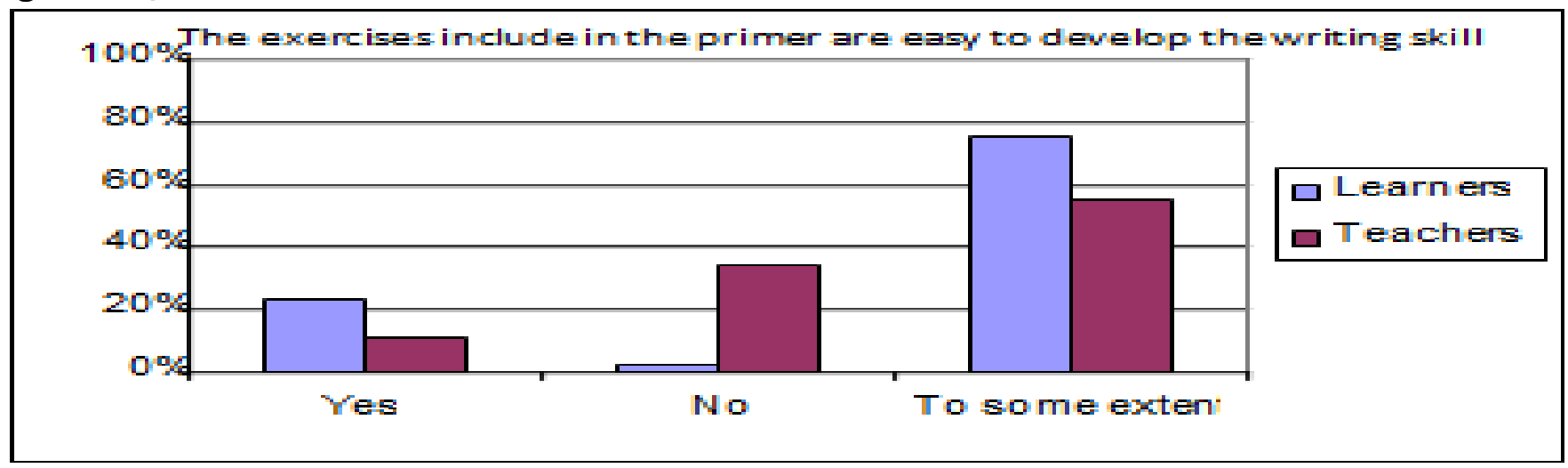

Keeping table (4.33) in view, 23\% students as shown in the first option indicates that tests added for practicing were easy to learn and to develop good writing skills. $2 \%$ of students do not agree that the tests placed on current primers were simple for practicing the alphabet by writing. The third bar shows that about $75 \%$ of students believe that the exercises included were somewhat easy and not too difficult to some extent.

Exercise including getting used to the first start was easy to learn to write the alphabet with an 
$11 \%$ teacher perspective. $34 \%$ of teachers negate that tests present in the current primers were simple for practicing the written alphabet. The third option shows that a 55\% teacher considers that for some, extending this test was easy and appropriate for writing books.

\section{Conclusion}

1. Most teachers and students feel that the present primer is somewhat interesting.

2. A rather large percentage of learners and teachers were of the opinion that the first textbook available is not that difficult and is easy.

3. It was also observed that a majority of teachers and students seemed to think that the wording of the sentences included in the current primer was easier to read but rather hard to write down.

4. Many teachers and students thought that the sentence structure present at the beginning was not that hard and was unchallenging to read. However, writing these sentences was rather challenging.

5. Many responses that were received indicated that a particular number of respondents thought that the test was easy and suitable for written practice.

6. Most respondents say it is better to place a photograph before meaning of the letter.

7. A majority of teachers and students hold the following views regarding the primer.

- I strongly disagree that the name containing Zair is not well defined in Primer.

- Most students and teachers agree with the idea that Zabar's concept was explained to others as an extension of the previous foundation.

- Most students and teachers generally agree with the idea that the concept of a pas explained to others extends to the beginning.

8. Most teachers suggest that pictures should be provided before the alphabetical description

9. The table above shows that from the point of view of many students and teachers the image added in the current primer were easy to grasp and comprehend.

\section{Discussion}

One of the most important goals of this study was to analyze the existing literature and former issues. The research findings that were deemed important for discussion in the study are the following. In this study it was observed that the text included in the former issues was complex and it appeared that it was challenging for students to grasp and write them. For the first respondents they pointed out that words containing two alphabets of the word as ko, jo need to be inserted at the beginning of the first letter. Students and teachers encouraged them to use the alphabet learned to read words easily. If topics in the discussion should be given to the discussion. Through interviews students and teachers find it easier to speak. Indicated by many respondents who agreed that they would prefer to read the alphabet in an orderly manner: alif bay pay and tay. The phonics learning program is also great. But students are unsatisfied from this approach. It was therefore necessary to adopt an integrated approach to sound and traditional approach. The original shape along with entire alphabetical structure should be taught. An adult student of reading and writing and writing the Quran using the traditional method of reading.

A majority of teachers and students thought that sentences added in current lesson were rather unchallenging and not very hard in terms of reading. However, written sentences were difficult for the learners to reproduce. Many respondents were of the opinion that image must precede the meaning of the alphabet. In former primer the images were shorter and less vague and less attractive. Every photo and imagery included in the primer should have attractive drawings and reflect the level of maturity according to the students 'life experience. 
There was only one image that was mentioned to teach the full concept of adult students' time and geometrical shapes were simply pasted on the text and were not illustrated separately. The vast majority of students and teachers agreed that the topic of time can be more efficiently illustrated with images. In this learning topic of the time it was aptly illustrated with pictures and the presentation of geometric shapes was also given the shapes placed on the existing primers

Raising the level of literacy development also plays an important role in literacy. The Jugnoo primer was eliminated owing to its shortcomings and especially the Pahla Qadam primer is taught in NCHD literacy centers. There seems to be a need for time that strategies must be properly focused on literacy programs.

In Pakistan there is no nationally defined or most common curriculum framework or low literacy rates for literacy programs. Many public and private organizations are therefore preparing for their first course. If literacy materials are provided with a specific strategy or set of low reading standards, it may be easier to introduce procedures for evaluating or assessing learners' skills.

Literacy materials should be categorized according to the needs and desires of the learners. Such matters must continue to be meaningful and must be addressed at the district and regional level. It seems appropriate to make material material more focused on the reader and the context in the relevant subject.

\section{Recommendations}

Following recommendations is based on our findings and conclusions.

1. Preparation of the primer should be in such a way that words should be built from the letters of the words that were mentioned or read previously.

2. Character teaching instruction the first structure of the alphabet should be included in the first foundation of writing skills. The foundation for literacy should describe the structure of the alphabet precisely, these contexts should be clear and distinct and easy for learners to comprehend.

3. Images and pictures must be utilized to portray the concept of time.

4. An easy-to-follow approach should be used; the primer should not be long it should be measured. The Islamic concept should show a thorough definition and various words should be included in the primer.

\section{References}

Anil Bordia, (1996), An Agenda for Adult Education Research: The South Asian Perspective", Archer D. and C Astha (1990), Kotra Development Block, southeast of Rajasthan State, India.

Ainsworth, S.E. (1997) Information technology and multiple representations: new opportunities new problems Journal of Information

Bhola, H.S, (1995) Functional literacy Workplace literacy and Technical and Vocational Education.

Interfaces and Policy Perspectives. UNESCO, Paris Blunch, Nils-Hugo, Verner Dorte, (2000).

Is Functional literacy a Prerequisite for Entering the labour Market? An Analysis of Determinants of Adult literacy and Earnings in Ghana Washington D.C., World Bank

Carm, Ellen, Berryman, N, Linken, (2001) Distance Basic Education in Lao P.D.R, Final Evaluation of UNESCO Project, LINS, Oslo University College, Norway

Bloem. L. (1992) Research to Practice: Bringing Children's Books to Adult Literacy Classrooms.

Clements, D. H. (2002), Computers in early childhood mathematics. Contemporary Issues in Early 
Childhood. 